\title{
Acknowledgement to Authors, Referees and Readers 2019
}

Marwan Sabbagh · Antonio Bertolotto

Published online: November 7, 2019

(C) The Author(s) 2019

Dear Reader,

As we compile the December 2019 issue of Neurology and Therapy, we thank our authors, our reviewers and our readers for their kind support of the journal.

2019 was a successful year for Neurology and Therapy; the journal has developed in all aspects in the past year. The number of downloads for the past 12 months is over 177,000 , an increase of 60,000 downloads when compared to the previous year. The number of submissions to Neurology and Therapy has also increased, and we will have published more than 45 articles by the end of the year. The journal CiteScore for the year up to October 2019 is 2.38 . We are also happy to inform you that the journal will be evaluated by Clarivate for an impact factor.

In 2019, we have had four experts in the field of Neurology join our editorial board: Dr. Silvia Tenembaum (Department of Neurology, National Pediatric Hospital Buenos Aires, Argentina), Dr. Pers Sørensen (Kobenhavns

Enhanced digital features To view enhanced digital features for this article go to https://doi.org/10.6084/ m9.figshare.10079075.

M. Sabbagh $(\varangle)$

Cleveland Clinic Lou Ruvo Center for Brain Health, Las Vegas, NV, USA

e-mail: Sabbagm@ccf.org

A. Bertolotto $(\square)$

University Hospital San Luigi Gonzaga, Turin, Italy

e-mail: antonio.bertolotto@gmail.com
Universitet, Department of Neurology, Copenhagen, Denmark), Dr. Victor M. Rivera (Baylor College of Medicine, Houston, Texas, USA) and Dr. Letizia Leocani (University Vita-Salute San Raffaele and IRCCS Hospital San Raffaele Scientific Institute, Italy). We are actively looking to expand the journal editorial board to meet the pace of journal development.

The five most popular articles in 2019, in terms of downloads from SpringerLink, are:

- Real-World Observational Evaluation of Hair Thinning in Patients with Multiple Sclerosis Receiving Teriflunomide: Is It an Issue in Clinical Practice? Hendin Travis L, Okai A, Cavalier S, et al. Neurol Ther (2018) 7:341. https://doi.org/10.1007/s40120-018-0107-y

- Antipsychotic-Related Movement Disorders: Drug-Induced Parkinsonism vs. Tardive Dyskinesia-Key Differences in Pathophysiology and Clinical Management. Ward KM, Citrome L. Neurol Ther (2018) 7:233. https:// doi.org/10.1007/s40120-018-0105-0.

- Emerging Immunotherapies for Parkinson Disease. Zella SMA, Metzdorf J, Ciftci E, et al. Neurol Ther (2019) 8:29. https://doi. org/10.1007/s40120-018-0122-z.

- An Overview of High-Efficacy Drugs for Multiple Sclerosis: Gulf Region Expert Opinion. Alroughani R., Inshasi JS, Deleu D, et al. Neurol Ther (2019) 8:13. https://doi.org/10. 1007/s40120-019-0129-0. 
- Vitamin D and Multiple Sclerosis: A Comprehensive Review. Sintzel MB, Rametta M, Reder AT. Neurol Ther (2018) 7:59. https:// doi.org/10.1007/s40120-017-0086-4.

We have been consistently publishing a number of articles on multiple sclerosis and other demyelinating disorders, cognitive disorders, movement disorders, among others, with our focus this year also expanding to mental health. A supplement issue on the "Peripheral Biomarkers for Alzheimer's disease" comprising seven review articles will also be published by the end of the year. In particular, we have been excited to see an increase in the usage of plain language summaries; these help make the published data comprehensible to a wider set of readers. Although we generally encourage the authors to submit these summaries along with manuscript so that they are published together with the article, as you see in this issue, we also accept them post-publication and host them online along with other enhanced features such as slide decks, videos, animations, audio abstracts, etc.

Thank you to our authors for choosing $\mathrm{Neu}$ rology and Therapy to publish your work. We are continually honoured by the contributions, the quality of which have greatly helped develop this journal.

We are also very grateful to our reviewers, some of whom have been registered as our Advisory Board members in the website and the others who we invite to join the board. We greatly appreciate your expertise and the effort you put in, both of which have facilitated rapid processing of the articles, thus maintaining short and efficient timelines. As always, we value your service and will be happy to publish your research as a token of our appreciation when accepted by peer review, upon completion of three reviews.

Similar to 2018, we will also be rewarding our most valued reviewers with a free publication regardless of the number of reviews. We will be contacting these reviewers personally and, with their permission, we will publish their names in January.

Finally, thank you to our readers. We hope that you have found the articles published throughout the year in Neurology and Therapy to be valuable to your own research and, most importantly, to your work with patients.

With Best Wishes, Marwan N. Sabbagh, Editor in Chief, US Antonio Bertolotto, Editor in Chief, EU

\section{ACKNOWLEDGEMENTS}

Funding. No funding or sponsorship was received for this study or publication of this article.

Authorship. All named authors meet the International Committee of Medical Journal Editors (ICMJE) criteria for authorship for this article, take responsibility for the integrity of the work as a whole, and have given their approval for this version to be published.

Disclosures. Marwan Sabbagh discloses the following: Harper Collins: Intellectual property rights (royalties or patent sales); Versanum Inc.: ownership interest (stock, stock options); Brain Health Inc: ownership interest (stock, stock options); Optimal Cognitive Health Company: ownership interest (stock, stock options); uMethod Health: ownership interest (stock, stock options); Neurotrope: ownership interest (stock, stock options); Allergan: consulting; Biogen: consulting; Bracket: consulting; Grifols: consulting; vTv therapeutics: consulting; Sanofi: consulting; Neurotrope: consulting; Cortexyme: consulting; Roche-Genentech: consulting. He has also received funding from Keep Memory Alive Foundation; National Institute of General Medical Sciences, Grant 5P20GM109025; National Institute of Health, Grants R01AG059008 and K01AG047279. Antonio Bertolotto 2019: advisory boards and/or speaker honoraria (Biogen, Novartis, Sanofi); grant support (Almiral, Biogen, Associazione San Luigi Gonzaga ONLUS, Fondazione per la Ricerca Biomedica ONLUS, Mylan, Novartis and the Italian Multiple Sclerosis Society).

Compliance with Ethics Guidelines. This article is based on previously conducted studies and does not contain any studies with human participants or animals performed by any of the authors. 
Open Access. This article is distributed under the terms of the Creative Commons Attribution-NonCommercial 4.0 International License (http://creativecommons.org/licenses/ by-nc/4.0/), which permits any noncommercial use, distribution, and reproduction in any medium, provided you give appropriate credit to the original author(s) and the source, provide a link to the Creative Commons license, and indicate if changes were made. 